(RESEARCH ARTICLE)

\title{
Evaluation of vaccination coverage for children aged 12-23 months admitted in N'Djamena Mother and Child University hospital (Chad)
}

\author{
Toralta J 1, *, Dillah M 1, Djaury D 1, Souam Nguele Silé 1, Youssouf HD 1, Gabkika B 2 \\ ${ }^{1}$ Department of pediatrics N'Djamena Mother and Child University hospital \\ 2 Department of obstetrics, N'Djamena Mother and Child University hospital.
}

Publication history: Received on 03 June 2020; revised on 12 June 2020; accepted on 14 June 2020

Article DOI: https://doi.org/10.30574/wjarr.2020.6.3.0184

\begin{abstract}
Vaccination is the administration of a vaccine to help the immune system develop protection from disease. It is the most effective method of preventing infectious diseases. The objective of the study was to assess vaccination coverage and show the habit and reluctance of the population on vaccination. This was a prospective and descriptive study from May $18^{\text {th }} 2017$ to November $30^{\text {th }} 2017$ about evaluation of vaccination coverage for children aged 12-23 months admitted in N'Djamena Mother and Child University hospital. Patients were recruited after checking the vaccination card and getting the consent by parent. Three hundred forty five children aged 12-23 months and their parents were recruited. There were 201 boys (58.25\%) for 144 girls (41.75\%) giving a sex ratio of 1.4 . The mothers with secondary level schooling were more represented with $34.78 \%$. Children that had received oral polio vaccine 1 and the pentavalent 1 were more represented. Long distance was the first reason of no vaccination (18.68\%). The majority of mothers (53.04\%) had known the five vaccination meeting and recognized by the national program of vaccination. One hundred forty six mothers $(45,21 \%)$ thought that it must happens a week after the birth. Measles was known by $34.90 \%$ of mothers. Fever was the most reported vaccine's side effects in $87.50 \%$. Vaccination coverage in N'Djamena Mother and Child University hospital is similar to those of Africans authors.
\end{abstract}

Keywords: Vaccination; Children 12-23 months; N'Djamena Mother and Child University Hospital

\section{Introduction}

Vaccination is the administration of a vaccine to help the immune system develop protection from disease. It is the most effective method of preventing infectious diseases $[1,2,3]$.

The world health organisation (WHO) estimate that vaccination averts 2-3 million deaths per year (in all age group), and up to 1,5 million children die each year due to diseases that could have been prevented by vaccination [4]. In Chad recent report on vaccination shown a national coverage of $25 \%$ for children aged 12-23 month are completely vaccinated with a high rate in urban areas (30\%) [5]. Despite this low rate, one can note a disparity for the coverage of different vaccines used. Faced with the resurgence of disease like measles, it seem essential to assess vaccination coverage and show the habit and reluctance of the population on vaccination

\section{Patients and methods}

This was a prospective and descriptive study of six month period from May $18^{\text {th }} 2017$ to November $30^{\text {th }} 2017$ about evaluation of vaccination coverage for children aged 12-23 months admitted in N'Djamena Mother and Child University hospital. Patients were recruited in the pediatrics emergency room or in the medical pediatrics hospitalization service. Children were referred or not, accompanied by parents.

\footnotetext{
* Corresponding author: Toralta J
} 
Data were registered during an individual interview.

A child is recognized totally vaccinated when he had received vaccine as show below

- $\quad$ BCG and oral polio vaccine at the birth

- Pentavalent (diphtheria vaccine+ pertussis vaccine + tetanus vaccine +Hib vaccine+ hepatitis vaccine) and oral polio vaccine 3 times at the $6^{\text {th }}$, the $10^{\text {th }}$ and the $14^{\text {th }}$ week after birth. Injectable polio vaccine was also given at the $14^{\text {th }}$ week

- Measles vaccine, yellow fever vaccine, Men A conjugate at the $9^{\text {th }}$ month.

Patients were recruited after checking the vaccination card and getting the consent by parents. Patients without vaccination card were not recruited.

Studied variables were: epidemiologic, reason of vaccination refusal, and the parent's knowledge on the vaccination. Data's were analyzed using SPSS 17.0

\section{Results}

Three hundred forty five children aged 12-23 months and their parents were recruited

\subsection{Socio demographic characteristics}

There were 201 boys (58.25\%) for 144 girls (41.75\%) giving a sex ratio of 1.4 .

\subsection{Socio-cultural characteristic of mothers}

Table 1 Educational level

\begin{tabular}{lll}
\hline Education level & number & \% \\
\hline Unschooled & 45 & 13.04 \\
Primary & 105 & 30.43 \\
Secondary & 120 & 34.78 \\
University & 75 & 21.75 \\
Total & & \\
\hline
\end{tabular}

The mothers with secondary level schooling were more represented with $34.78 \%$.Two hundred sixty six children were coming from low financial resource, and the majority of mothers (51.32\%) aged 25-35 years.

\subsection{Immunization status}

Table 2 Vaccination coverage

\begin{tabular}{lll}
\hline Vaccine & n & \% \\
\hline BCG & 318 & 92.17 \\
VPO & 318 & 92.17 \\
Penta 1 & 315 & 97.22 \\
VPO 1 & 315 & 97.22 \\
Penta 2 & 279 & 95.87 \\
VPO 2 & 270 & 92.78 \\
Penta 3 & 189 & 75.90 \\
VPO 3 & 318 & 77.10 \\
Measles vaccine & 147 & 81.66 \\
yellow fever vaccine & 147 & 81.66 \\
\hline
\end{tabular}


Children that had received oral polio vaccine 1 and the pentavalent 1 were more represented.

\subsection{Reason of non-vaccination}

Table 3 Reason of non-vaccination

\begin{tabular}{lll}
\hline Reason of non-vaccination & $\mathbf{n}$ & $\mathbf{\%}$ \\
\hline Long distance & 144 & 18.68 \\
Long wait & 111 & 14.39 \\
Vaccine made child sterile & 3 & 0.39 \\
Lack of information & 51 & 6.61 \\
Unavailability of vaccine & 39 & 5.05 \\
Vaccine made child ill & 87 & 11.28 \\
Unavailability of vaccinator & 18 & 2.33 \\
Child 'mother busy & 81 & 10.50 \\
No confidence on the vaccine & 126 & 16.38 \\
Fear of vaccine side effects & 111 & 14.39 \\
\hline
\end{tabular}

Long distance was the first reason of no vaccination $(18.68 \%)$

\subsection{Knowledge on vaccination and diseases targeted by the national program of vaccination}

The majority of mothers (53.04\%) had known the five vaccination meeting and recognized by the national program of vaccination.

One hundred and eleven (32.17\%) mother thought that the first dose of vaccine must be given at the birth. One hundred forty six mothers $(45,21 \%)$ thought that it must happens a week after the birth.

Table4Knowledge on vaccination and Targeted diseases by the national program of vaccination

\begin{tabular}{lll}
\hline Targeted disease & $\mathbf{n}$ & $\mathbf{\%}$ \\
\hline Tuberculosis & 24 & 7.54 \\
Diphtheria & 0 & 0 \\
Tetanus & 48 & 15.10 \\
Pertussis & 6 & 1.88 \\
Poliomyelitis & 84 & 26.41 \\
measles & 111 & 34.90 \\
Hepatitis B & 27 & 8.6 \\
Yelowfever & 18 & 5.66 \\
Haemophilus Influenza & 0 & 0 \\
\hline
\end{tabular}

Measles was known by $34.90 \%$ of mothers. 
Table 5 Vaccine's side effects reported by mothers

\begin{tabular}{lll}
\hline side effects & $\mathbf{n}$ & (\%) \\
\hline Fever & 273 & 87.50 \\
Diarrhea & 1 & 0.29 \\
Paralysis & 5 & 1.45 \\
No idea & 30 & 9.61 \\
\hline
\end{tabular}

Fever was the most reported vaccine's side effects with $87.50 \%$

\section{Discussion}

Like some African authors $(6,7)$ we noted a high proportion of boy than girl. There is no evidence explaining this difference. Factors like demographic can be incriminated.

According to Chad national report about vaccine, the proportions of mothers attending with their child to vaccination meeting are important for those for the primary and secondary level respectively $33 \%$ and $46 \%$. This study confirms these findings with respectively $30.43 \%$ and $34.78 \%$ mothers with primary and secondary levels.

Unschooled mothers had represented 13.04\%. This result is similar to those of Rahajasoamamonjy M. [8] and Berete B (9) which reported respectively $11.9 \%$ and $42.9 \%$ of unschooled mothers. Some authors like Veronique's (10) in Benin had not recorded unschooled mothers. Cultural factors can explain this result $(11,12)$. Then schooling seems to be an element that allowing mother to accept attending to vaccination meeting.

vaccine coverage was : $92.17 \%$ for BCG, 92,17\% for OPV, 97,22\% for Penta1 and OPV1; 95.87\% for Penta2 ; 92.78\% for OPV 2 , 75.90 \% for Penta3, 77.10\% for OPV 3 and 81,66 \% form measles vaccine and yellow fever vaccine. Ours result are similar to those of Doumbia (6) which reported respectively92. $2 \%$ for BCG and OPV, 96.2 \% for Penta1, Penta2, OPV1, OPV2, $94.8 \%$ for Penta3 andOPV3, $80.8 \%$ for measles vaccine and yellow fever vaccine. Therefore, Sacko R (13) noted a low proportion than ours respectively $82.4 \%$ and 39\% for BCG and measles vaccine. According to Chad's national vaccination report, the vaccination coverage is linked with different strategy of vaccination. National campaigns of vaccination are recognized as possibility to reach children that can't attend vaccination meeting on hospital. In Chad, routine vaccination in the most used manner to vaccinate children. In the same way, Chippaux et al (14) in Senegal in 2006 said that organization of health service is factor increasing the vaccination coverage.

The main reasons ofnon-vaccination reported in this study were: long distance (18.68\%), no confidence on the vaccine (16.38\%). For Rahajasoamamonjy M. [8] and Doumbia P (6) the main reasonswere unavailability of vaccine, delivery occurring at home and lack of information respectively $57 \%$ and $90 \%$.

The majority of mothers (53.04\%) had known the five vaccination meeting and the targeted diseases by the national program of vaccination. This result is better than those of Sory 0 (7) and Gervais L (15) that noted respectively $6.8 \%$ and $26.2 \%$ of mothers knowing the number and the period of vaccination meeting.

The majority of mother in this study (53.04\%) had known the targeted diseases by the national program of vaccination. This findings high than the 8.8\% reported by Sory (7).Those authors like Gervais L (15) and Doumbia P (6) noted a better proportion than our respectively $93.3 \%$ and $99.5 \%$ for knowledge on the targeted diseases by the national program of vaccination

Mothers' knowledge on targeted diseases by the national program of vaccination was: measles (34.90\%), poliomyelitis $(26.41 \%)$ tetanus (15.10\%).These results reinforce those of Sissoko (16) in Mali who reported tetanus as the main targeted disease known by mothers with $18.8 \%$.

Fever was the most reported side effect of vaccine in this study with $87.5 \%$. Ours finding is similar to those of Sissoko (16) and Doumbia (6) which noted fever as reported side effects respectively $83.42 \%$ and $97.7 \%$. These finding can be explained by the fact that fever is easily noticed by the population. 


\section{Conclusion}

Vaccination coverage in N'Djamena Mother and Child University hospital is similar to those of Africans authors. Immunization status, knowledge on side effects on targeted diseases by the national program of vaccination is linked with factor like schooling and cultural phenomena.

\section{Compliance with ethical standards}

\section{Acknowledgments}

All authors approve the submission of this work.

\section{Disclosure of conflict of interest}

All authors have declared that there is no conflict of interest.

\section{Statement of ethical approval}

All authors approve the submission of this work.

\section{Statement of informed consent}

For this survey we have obtained the agreement of the national Ethics Committee, Director of N'Djamena Mother and Child University hospital.

\section{References}

[1] Fiore AE, Bridges CB and Cox NJ. (2009). Seasonal influenza vaccines. Current Topics in Microbiology and Immunology, 333, 43-82.

[2] Chang Y, Brewer NT, Rina's AC, Schmitt K and Smith JS. (2009). "Evaluating the impact of human papillomavirus vaccines". Vaccine. July, 27(32), 4355-62.

[3] Liesegang TJ. (2009). "Varicella zoster virus vaccines: effective, but concerns linger". Canadian Journal of Ophthalmology August, 44(4), 379-84.

[4] Ehreth J. (2003). "The global value of vaccination". Vaccine January, 21(7-8), 596-600.

[5] Demographic and health survey of Chad. (2015).

[6] Doumbia P. (2009). Evaluation on vaccination coverage for children aged 12-23 months. Thesis of medicine, University of Bamako, Mali, 68- 70.

[7] Sory 0. (2006). Evaluation of vaccination coverage of children aged 12 à 23 months and their mothers. Thesis of medicine,University of Bamako,Mali , 95 -100.

[8] Rahajasoamamonjy M. (2008). Evaluation of the vaccination coverage in ambohipo. Thesis of medicine, University of Antananarivo,Madagascar, 78-90.

[9] Bérété B. (2006). Characteristic of men and women interviewed, Guinea' demographic and health survey 2005, first edition, Calverton Maryland USA, 33-56.

[10] Veronique S. (2009). Evaluation of the vaccination coverage of children aged 11-23 months and knowledge attitude and practice of mothers on national program of vaccination in Ouiddah.Thesis of medicine, University of Ouiddah, Benin, 35-45.

[11] Fourn L andAde GA. (2005). Vaccination report. Med Afr Noire, 52(03), 145-150.

[12] Eric WC and Nacoulma KL. (2006). Assessment of the immunization status of children with sickle cell disease in the city of Ouagadougou (Burkina Faso). Francophone study and research notebooks / Health, 16(3), 155-160.

[13] Sacko R. (2000). Evaluation of vaccination coverage and Analysis of the reasons for non-vaccination in the GAO district. Mali. Thesis of medicine, university of Bamako,Mali ,81-92.

[14] Chipaux JP, Marra A and Diallo A. (2006). Analysis of the evolution of vaccination coverage in Niakhar in Senegal, rural region of Senegal between 1984 and 2003. Med Trop, 28, 57 -9. 
[15] Gervais L. (2008). Assessment of vaccination coverage in children 12 to 23 months and the reasons for nonvaccination. Thesis of medicine, university of TIKO (Cameroon), 51-60.

[16] Sissoko N. (2004). Evaluation of the vaccination coverage of children from 12 to 23 months and of mothers from 15 to 49 years in commune $\mathrm{V}$ of the district of Bamako by the LQAS method from April to May 2004. Thesis of medicine, University of Bamako, 70-80.

\section{How to cite this article}

Toralta J, Dillah M, Djaury D, SouamNgueleSilé, Youssouf HD, Gabkika B. (2020). Evaluation of vaccination coverage for children aged 12-23 months admitted in N'Djamena Mother and Child University hospital (Chad). World Journal of Advanced Research and Reviews, 6(3), 136-141. 